\title{
Omental Transplantation for limb salvage in Buerger's disease - a study in a tertiary care hospital, Bhopal
}

\author{
Krishnanand ${ }^{1}$, Chanchlani $\mathbf{R}^{2}$, \\ ${ }^{1}$ Dr Krishnanand, Associate Professor, ${ }^{2}$ Dr Roshan Chanchlani, Assistant Professor, Both from Department of Surgery, Chirayu \\ Medical College \& Hospital, Bhopal, M P, India.
}

Address for correspondence: Dr Roshan Chanchalani, Email: roshanchanchlani@gmail.com

\begin{abstract}
Introduction: In recent years, it has become evident that peripheral vascular disease is an important predictor of substantial coronary and cerebral vascular risk. The majority of patients present with an advanced stage of ischemia; hence, most of them require surgical intervention in the form of lumbar Sympathectomy, Omentopexy, or major or minor amputations. Patients presenting with terminal limb ischemia due to thromboangitis obliterans often have no hope for limb salvage; for such cases, omental transplantation offers a procedure which can result in improved limb circulation and limb salvage. Material and Methods: This is a prospective study done on a group of 25 patients. The patients were diagnosed on the basis of history, clinical examination and investigations like Colour doppler and femoral arteriography in few cases. Omentopexy was done and patients were assessed on $7^{\text {th }}$ post operative day, after 1 month and 3 months after the procedure. Results: On an average the patients smoked between 10- 25 beedis per day. Amongst these cases 10 cases had non-healing ulcers and 15 had dry gangrene of toes or forefoot, with rest pain. In 15 cases, popliteal artery pulsation was absent. After operative procedure intermittent claudication and rest pain were relieved in 80 and $100 \%$ of the patients respectively. Healing of ulcer occurred in 9 out of 10 patients (90\%). Conclusion: Buerger's disease is limb threatening condition occurring in productive age group and its management is challenging. If carried out with right technique and knowledge about vascular omental arcade, the results of omentopexy are good.
\end{abstract}

Keywords: Buerger's disease, Omental transplant, Omental transposition, Peripheral Vascular disease, Thromoboangitis Obliterans

\section{Introduction}

Buerger's disease (Thromboangitis Obliterans) is a condition characterised by segmental occlusion of small and medium sized arteries of the lower and sometimes of upper extremities in young male smokers, often associated with migratory thrombophlebitis. ${ }^{1,2}$. In recent years, it has become evident that Peripheral Vascular Disease is an

Manuscript received: $04^{\text {th }}$ Aug 2013

Reviewed: $13^{\text {th }}$ Aug 2013

Author Corrected: $20^{\text {th }}$ Aug 2013

Accepted for Publication: 24 $4^{\text {th }}$ Aug 2013 important predictor of substantial coronary and cerebral vascular risk. $^{3-6}$. With the exception of cessation of smoking, none of these measures is curative. Drug therapy is of little benefit. ${ }^{2,}$ 7-10 Surgical treatment options have consisted of sympathectomy, direct arterial surgery, adrenalectomy, and amputation as a last resort. Also, patients who have ischemic signs and symptoms have been offered sympathectomy, despite the fact that relapses are frequent due to normalisation of vasomotor tone 
within two weeks to six months after operation. ${ }^{11-13}$. Daniel et $\mathrm{al}^{14}$ report in this article that omental transfer for revascularization of extremities will post pone amputation. Casten and Alday first studied omental transplantation. Goldsmith et $\mathrm{al}^{15,16}$ discovered lipid fraction from the omentum exerts angiogenic properties. Omentopexy acts by increasing the collateral circulation as it contains angiogenic factor. Arterial reconstruction is usually impossible due to distal nature of the disease and carries a high failure rate. These considerations have always prompted surgeons to look for an alternative solution in the form of omental transfer. Omentopexy is a surgical procedure whereby the greater omentum is sutured or placed to a nearby organ to improve vascularity.

\section{Material and Methods}

Study design: This is a prospective study comprising of patients of peripheral vascular diseases of lower limbs.

Study Place: Department of Surgery, Chirayu Medical College and Hospital, Bhopal.

Study period: May 2011 to June 2013.

Sample size: A total of 25 patients presenting with sign and symptoms of Peripheral vascular disease.

Exclusion criteria: Obese, diabetic and patients presenting with wet gangrene.
Procedure: The patients were seen in surgical outdoor in emergency and routine hours and were diagnosed on the basis of history, clinical examination and investigations like Coloured doppler and femoral arteriography in few cases.

All patients underwent a Doppler scan of the lower limb prior to Surgery. The Doppler study was done mainly to demonstrate the block and the flow in the distal vessels. Surgery was done under general anaesthesia, supine position, midline vertical incision, omentum mobilized along with its vascular arcade (Figure 1), subcutaneous tunnelling done (Figure 2) and placed at the distal ulcer site (Figure 3). In the post operative period, patient were kept nil orally for 48 hours and switched on to oral feeds once the bowel sounds returned. Patients were advised to keep the limb in extension for 3-4 days. For assessment of effect of omentopexy the criteria used were both subjective and objective. Subjective assessment was done by observing improvement in symptoms and objective assessment was assessed with:

1) Improvement in the local skin temperature.

2) Relief in pain.

3) Healing of ulcers and amputation site.

4) Measurement of oxygen saturation by pulse oximetry.

The patients were assessed after 7 days, 1 month and 3 months after undergoing the procedure.

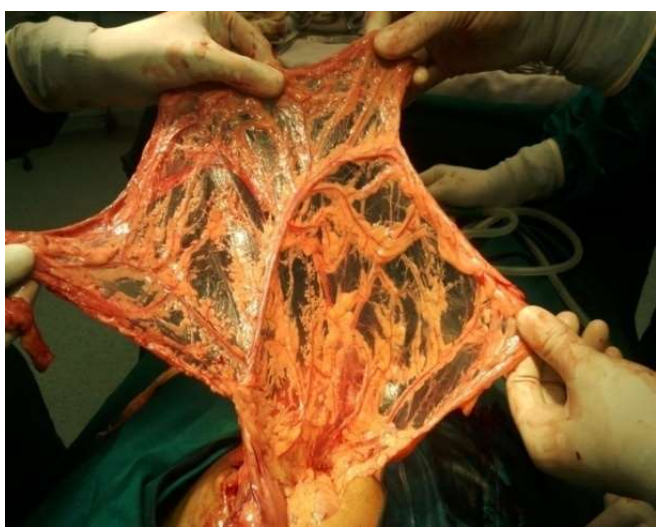

Figure 1: Vascular Omental Arcade

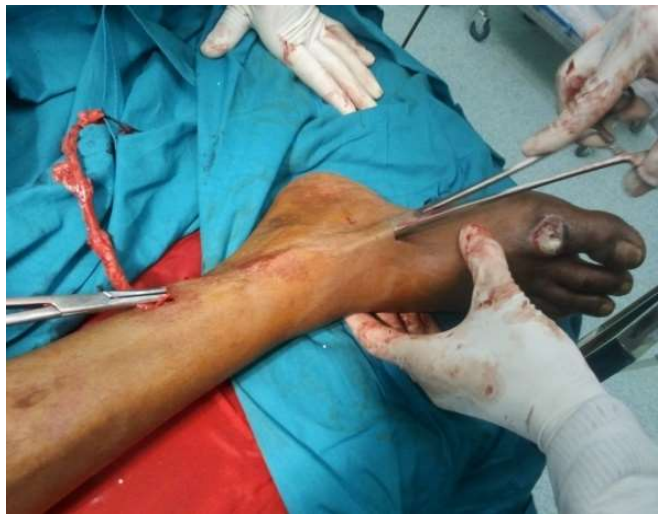

Figure 2: Subcutanous Tunneling 


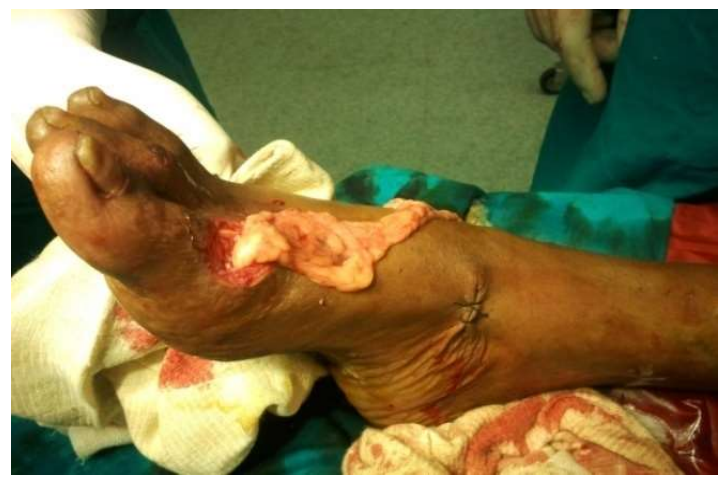

Figure 3: Omentum placed at distal ulcer site

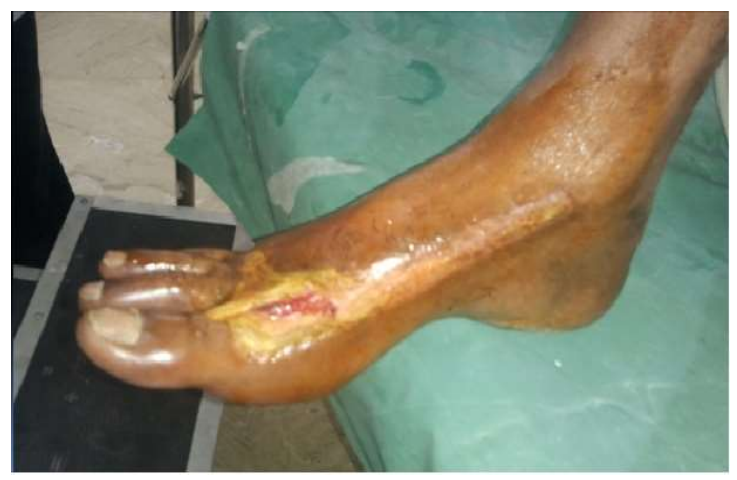

Figure 4: Healed wound after one month

\section{Results}

The youngest patient in the study was $25 \mathrm{yrs}$ old and the oldest was 60yrs. All of the studied patients were male. All of the patients were from low socio-economic status. Most of them were labourers.

None of these patients were on any medications except oral analgesics before admission. All the patients in the study were nondiabetic and normotensive at the time of admission

Table 1: Clinical Presentations of cases according to symptoms

\begin{tabular}{|c|c|c|}
\hline Symptoms & No. of patients & Percentage (\%) \\
\hline Intermittent claudication & 25 & 60 \\
\hline Rest pain & 15 & 40 \\
\hline Ulceration & 10 & 60 \\
\hline Gangrene & 15 & \\
\hline
\end{tabular}

All the patients presented with pain in lower limbs and intermittent claudication, most of them had rest pain, ulceration and gangrene.

Table 2: Patients with their habits

\begin{tabular}{|c|c|c|}
\hline Addiction & No. of patients & Percentage (\%) \\
\hline Smoking & 25 & 100 \\
\hline Alcohol & 15 & 60 \\
\hline Smokeless tobacco & 5 & 20 \\
\hline
\end{tabular}

All the patients in our study were beedi smokers (100\%), $15(60 \%)$ of them were also occasional alcoholics. $5(20 \%)$ of them also used smokeless tobacco in pan chewing. 
Table 3: Duration of Smoking

\begin{tabular}{|c|c|c|}
\hline Duration of smoking (in yrs) & No. of patients & Percentage (\%) \\
\hline$\leq \mathbf{1 0}$ yrs & 6 & 24 \\
\hline $\mathbf{1 0 - 2 0}$ yrs & 14 & 56 \\
\hline $\mathbf{2 0 - 3 0}$ yrs & 5 & 20 \\
\hline
\end{tabular}

Most of our patients were smoking for more than 10 years and $20 \%$ for last 20 years.

Table 4: Peripheral arterial Pulses

\begin{tabular}{|c|c|c|c|}
\hline Arterial Pulsation & $\begin{array}{c}\text { Absent } \\
\text { (n) }\end{array}$ & $\begin{array}{c}\text { Weak } \\
\text { (n) }\end{array}$ & $\begin{array}{c}\text { Normal } \\
\text { (n) }\end{array}$ \\
\hline Dorsalis Pedis Artery & 25 & 0 & 0 \\
\hline Anterior Tibial Artery & 25 & 0 & 2 \\
\hline Posterior Tibial Artery & 23 & 3 & 2 \\
\hline Popliteal Artery & 20 & 3 & 22 \\
\hline Femoral Artery & 0 & 0 & 0 \\
\hline
\end{tabular}

The pulses were assessed both by clinical examination and a hand held Doppler probe. Dorsalis Pedis, Anterial Tibial and Posterior Tibial were absent in most of the patients.

Table 5: Extent of the disease

\begin{tabular}{|c|c|c|}
\hline Disease Extent & No. of patients & $\%$ \\
\hline Disease restricted to one limb & 25 & 100 \\
\hline Disease involving B/L lower limbs & 13 & 52 \\
\hline Disease involving B/L lower limbs and upper limbs & 1 & 4 \\
\hline
\end{tabular}

All the patients in the study presented with symptoms involving only one lower limb. But during clinical examination, $52 \%$ of patients also had involvement of opposite lower limb. $4 \%$ of them had clinical involvement of upper limb.

Table 6: Duration of Hospital stay

\begin{tabular}{|c|c|c|}
\hline Duration of hospital stay & No. of patients & Percentage (\%) \\
\hline$<$ 2 days & 1 & 67 \\
\hline $\mathbf{2 0 - 3 0}$ days & 17 & 16 \\
\hline $\mathbf{3 0 - 4 0}$ days & 4 & 12 \\
\hline$>\mathbf{4 0}$ days 5 & 3 & 67 \\
\hline
\end{tabular}

In post operative period, 10 patients had postoperative infection of wounds. All of these patients were treated with regular dressing and antibiotic according to culture and sensitivity reports. Duration of hospital stay varied from 15-90 days. Most of the patients stayed for 20-30 days. 
The length of post operative stay was increased in the patients due to wound infections and due to no improvement following the procedure. During follow-up the patients were assessed at $7^{\text {th }}$ day, 1 month (figure 4) and 3 months following intervention.

Table 7: Follow up Results showing symptomatic improvement

\begin{tabular}{|c|c|c|c|c|}
\hline Symptom & $\begin{array}{c}\text { At the time of diagnosis } \\
\text { No (\%) }\end{array}$ & $\begin{array}{c}\text { 7th day } \\
\text { No (\%) }\end{array}$ & $\begin{array}{c}\text { 1st Month } \\
\text { No (\%) }\end{array}$ & $\begin{array}{c}\text { 3rd Month } \\
\text { No (\%) }\end{array}$ \\
\hline Intermittent claudication & $25(100)$ & $17(66)$ & $7(27)$ & $4(17)$ \\
\hline Rest pain & $15(60)$ & $7(27)$ & $4(17)$ & $0(0)$ \\
\hline Healing of ulcer & $10(40)$ & $9(37)$ & $7(27)$ & $1(4)$ \\
\hline Healing of amputated site & $15(60)$ & $15(60)$ & $11(43)$ & $4(17)$ \\
\hline
\end{tabular}

Most of the patients had symptomatic improvement in all major symptoms i.e. intermittent claudication and Rest pain.

Table 8: saturation of limb during follow up

\begin{tabular}{|c|c|c|c|c|}
\hline O2 saturation & At time of diagnosis & $7^{\text {th }}$ day & $1^{\text {st }}$ month & $3^{\text {rd }}$ month \\
\hline & 70 & 80 & 90 & 96 \\
\hline
\end{tabular}

Oxygen saturation was increased in toes during follow up.

\section{Discussion}

Buerger's disease is a limb-threatening condition occurring in the young and productive age group and its management has always been a challenging problem. ${ }^{17}$. In patients with critical limb ischemia, surgery is required to salvage the limb. Traditionally, patients who have ischemic signs and symptoms have been offered sympathectomy despite the fact that relapses are frequent due to normalization of vasomotor tone within 2 weeks to 6 months after operation. Sympathectomy removes the vasoconstrictor tone improving blood flow and promoting ulcer healing and improving pain. But it does not increase flow to ischemic muscles and thus no improvements occur in claudication distance. Its long term role in chronically dilated ischemic vessels is also questionable ${ }^{18,19}$ Direct revascularization surgeries are not possible due to diffuse involvement and absence of distal target vessel. ${ }^{20}$

In patients who are in imminent danger of requiring major amputation, omental pedicled transplantation is a viable alternative for limb salvage and also significantly improves signs and symptoms. Babu et $\mathrm{al}^{21}$ report in this article that there was relief in intermittent claudication in $92 \%$ patients with TAO, relief from rest pain in $86 \%$, healing of ulcers in $100 \%$ of their patients. $14 \%$ of their patients required major amputation. Ranwaka et $\mathrm{al}^{22}$ obtained relief in intermittent claudication in $86.6 \%$, from rest pain in $66.6 \%$ and healing of ulcers in $80 \%$ in their patients. The results in our study are consistent with these results of some previous studies. Subodh.et $\mathrm{al}^{23}$ reported in this article to find out the mechanism by which the omental graft increases the blood supply to the limbs. They performed Doppler ultrasound studies and celiac digital subtraction angiography to study the circulation though the omental graft. Only in 6 out of 12 patients could they visualize omental vessels till mid-thigh and only in four up to the knee joint. They concluded that omental transposition acts not by significantly supplying extra blood to the limbs but by acting locally on the limb musculature and probably causing increased collateral circulation. Although in the
Available online at: www.ijmrr.in
96 | $\mathrm{P}$ a g e 
absence of such investigating facilities and financial constraints, we were not able to visualize omental vessels but we could certainly appreciate an excellent symptomatic relief obtained in these patients. There was immediate relief of pain, the progression of gangrene stopped, and ulcers healed; a certain major amputation was avoided in $90 \%$ of patients. Another interesting finding in the present series was that most of the patients experienced pain relief, immediately following surgery.

Possible causes may be (i) Psychological relief that operation has been performed (ii) Bed rest (hospital admission) (iii) Supervision and almost complete stoppage of smoking leading to remission of the disease. In the present study, objective tests were carried out to see improvement in circulation. Skin temperature increased in $90 \%$ of patients. Pulse oximetry, an excellent method of assessing limb perfusion revealed a clear benefit in tissue oxygenation after pedicled omental transplantation.

\section{Conclusion}

Omental transplantation offers a procedure which can result in improved limb circulation and limb salvage in patients with Buergers disease.with limb ischemia. Omental transplantation induces neo-angiogenesis thereby improving circulation of surrounding tissues.

Single stage lumbar sympathectomy and omental transplantation is a better procedure in end state Thrombo angitis obliterans. Omental transplantation is an operation, which can be performed by general surgeon and immediate improvement in symptoms cannot be explained on psychological basis alone as was demonstrated by increase in skin temperature and improved tissue oxygenation by pulse oximetry. The present study has short comings in the form of (i) short duration of follow up (ii) no Doppler or angiographic evidence during follow up (iii) No histological proof of neovascularization of muscles. (iv) Abdominal approach \& bowel handling (v) Small series. The present study however proved beyond doubt the role of omental transplantation in clinical improvement and as a limb salvage procedure in Buerger's disease. Long term prospective randomised and controlled clinical trials with good follow up is needed to establish this procedure as the first line management of patients with Buerger's disease.

\section{Funding: Nil}

\section{Conflict of interest: Nil}

\section{Permission from IRB: Yes}

\section{References}

1. Buerger L. Thromboangitis Obliterans: a study of the vascular lesions leading to presenile spontaneous gangrene. Am J Med Sci 1908; 136:567-580.

2. Olin JW. Thromboangitis Obliterans (Buerger's Disease). New Eng1 J Med 2000; 343:864-869

3. Ogren M, Hedblad B, Isacsson S. Ten year cerebrovascular morbidity and mortality in 68 year old men with asymptomatic carotid stenosis. BMJ 1995; 310 : $1294-129$

4. Tsai A, Folsom A, Rosamond W, Jones D. Anklebrachial index and 7-year ischemic stroke incidence. The ARIC Study. Stroke 2001; 32: 1721-1724.

5. Bainton D, Sweetnam P, Baker I, Elwood P. Peripheral vascular disease: consequence for survival and association with risk factors in the Speedwell prospective heart disease study. Br Heart J 1994; 72: 128-132.

6. Newman A, Shemanski L, Manolio T. Ankle-arm index as a predictor of cardiovascular disease and mortality in the Cardiovascular Health Study. Arterioscler Thromb Vasc Biol 1999; 19: 538-545.

7. Fiessinger JN, Schafer M. Trial of iloprost versus aspirin treatment for critical limb ischaemia of thromboangitis obliterans. The TAO study. Lancet 1990; 335:555-557 
8. Talwar S, Choudhary SK, Bhan A. Buerger's disease. Indian Journal of Cardiology 1998; 1:31-34.

9. Stricht VJ, Goldstein M, Flamand JP, Belenger J. Evolution and prognosis of thromboangitis obliterans. $\mathrm{J}$ Cardiovasc Surg (Torino)1973; 14:9-16

10. Kunlin J, Lengua F, Testart J, Pajot A. F. Thromboangiosis or thromboangitis treated by adrenalectomy and sympathectomy from 1942 to 1962 . J Cardiovasc Surg (Torino) $1973 ; 14: 21-27$

11. Lau H, Cheng SK. Buerger's disease in Hong Kong: a review of 89 cases. Aust NZ J Surg 1997; 67:264-269

12. Sasajima T, Kubo Y, Inaba M, Goh K. Plantar or dorsalis pedis artery bypass in Buerger's disease. Ann Vasc Surg 1994; 8:248-257

13. Stricht VJ, Goldstein M, Flamand JP, Belenger J. Evolution and prognosis of thromboangitis obliterans. $\mathrm{J}$ Cardiovasc Surg (Torino)1973; 14:9-16

14. Casten DF, Alday ES. Omental transfer for revascularization of the extremities. Surg Gynecol Obstet $1971 ; 123: 301-304$

15. Goldsmith HS, Griffith AL, Catsimpoolas N. Increased vascular perfusion after administration of an omental lipid fraction. Surg Gynecol Obstet 1986;

162:579-583.

16. Goldsmith HS, Griffith AL, Kupferman A, Catsimpoolas N. Lipid Angiogenic factor from Omentum. JAMA 1984; 252:2034-2036.
17. Talwar S, Choudhary S K. Omentopexy for limb salvage in Buerger's disease: indications, technique and results. J Postgrad Med 2001 [cited 2013 Aug 1];47:137

18. Chander J, Singh L, Lal P, Jain A, Lal P, Ramteke VK. Retroperitoneoscopic lumbar sypathectomy for buerger's disease: a novel technique. J Soc Laproendosc Surg. 2004;8(3):291-296.

19. Shionoya S. Buerger's disease (Thromboangiitis Obliterans). Vascular surgery, vol. 4. Philadelphia: RB Rutherford, WB Saunders; 2010. pp. 235-245.

20. Lazarides MK, Georgiadis GS, Papas TT, Nikolopoulos ES. Diagnostic criteria and treatment of Buerger's disease: a review. Int J Low Extrem Wounds. 2006;5(2):89-95

21. Babu RD, Menon NG, Vaidyanathan S. Pedicled omental transplantation for end stage. Buerger's disease as a limb salvage procedure. Indian Journal of Surgery 1990; $52 ; 463-71$.

22. Ranwaka R, Sharma R, Mathur SN, Sachdeva G. Revascularisation of limbs by omental transfer. Ind J Surg. $1999 ; 61: 364-366$.

23. Subodh S., Mohan JC, Malik VK, Omentopexy in limbs revascularization in Buerger's disease. Indian Heart J 1994; $46 ; 355-357$.

\section{How to cite this article?}

Krishnanand, Chanchlani R. Omental Transplantation for limb salvage in Buerger's disease - a study in a tertiary care hospital, Bhopal. Int J Med Res Rev 2013;1(3):92-98. doi:10.17511/ijmrr.2013.i03.04 